\title{
Air pollution and health: Evidence from epidemiological studies and population impact
}

\author{
FranCESCO Forastiere \\ CNR-Irib - Palermo, Italy \\ King's College - London, UK \\ Carla AnCona \\ Dipartimento di Epidemiologia, Servizio Sanitario Regionale del Lazio - Roma, Italy
}

Summary. - Outdoor air pollution - in particular particulate matter, nitrogen dioxide and ozone- can exert its effects on health after acute (short-term) and chronic (long-term) exposures. Short-term exposures increase the probability of the onset of acute diseases within a few days, such as myocardial infarction or stroke, or even death in the case of susceptible individuals. Long-term exposures are associated with decreased survival and incidence of several non-communicable diseases, including cardiorespiratory conditions and lung cancer. In Europe, the large ESCAPE project (European Study of Cohorts for Air Pollution Effects www.escapeproject.eu) evaluated the chronic effects of air pollution in the cohorts of adult subjects. The results of ESCAPE show an association between chronic exposure to air pollutants and natural mortality, cardiovascular events, lung, brain, breast and digestive tract cancer. The recent joint statement of the European Respiratory Society and the American Respiratory Society clarifies the wide spectrum of adverse effects of pollution, including "new" diseases such as neurological and metabolic syndrome previously not studied. The estimates by the Global Burden of Disease provide nowadays indications that air pollution causes illness and mortality, just after diet, smoking, hypertension and diabetes: 4.2 million premature deaths a year worldwide. Ischemic heart disease, stroke, chronic obstructive pulmonary disease, acute lower respiratory infections are the main conditions associated with air-pollution-related mortality. 


\section{1. - Introduction}

According to United Nations estimates, by 2050, almost $70 \%$ of the world's population will be living in urban environments, due to increased employment opportunities, access to goods and services, innovation and opportunities for cultural and political participation [1]. However, the population living in cities suffers from problems related to inadequate housing and transport, waste management, heat islands, and air quality that does not comply with World Health Organization (WHO) guidelines. The present contribution summarizes the current knowledge on the health effects of air pollution and its impact worldwide and indicate a specific role for the health professionals to act in order to protect public health.

\section{2. - The health impact of pollution in the world}

Globally, $92 \%$ of the population lives in places where air quality does not comply with World Health Organization (WHO) guidelines. In total, 4.2 million deaths were attributed to outdoor air pollution in 2016 (airborne particulate matter, PM2.5), an estimate that has remained constant since 1990. The current forecasts estimate a doubling of attributable deaths by 2050, largely due to rising pollution levels in rapidly industrialising Asian countries and a global ageing population resulting in higher rates of non-communicable diseases.

The international project Global Burden of Disease (GBD) [2], since 2012, periodically evaluates the health status of 195 nations around the world by examining causes of death, disease and risk factors. There are clear differences in the world in life expectancy at birth; Italy, for example, after Japan, has a longer life expectancy than all other countries, both for men and women, The GBD also identifies, at country-level, the relevant risk factors responsible for early mortality. When looking at global data, the well-known individual risk factors such as blood pressure, body mass index, cigarette smoking and reduced physical activity are in the first places. Alongside these, the GBD places the emphasis on air pollution which is the sixth leading cause of illness and disability in the world. One important condition, cardiovascular disease (CVD), is the leading cause of death worldwide, with more than 17 million premature deaths in 2016, and exposure to environmental pollutants is responsible for about 3.3 million of these deaths, mainly from ischemic heart disease (IHD) and stroke (http://ghdx.healthdata.org/gbd-results-tool). In 2013, the WHO International Agency for Research on Cancer established that there is sufficient evidence of the carcinogenicity of airborne particulate matter (PM10 and PM2.5), particularly lung cancer. Compared to other environmental factors such as water, soil or electromagnetic wave pollution, air pollution is by far the most important environmental risk factor. In Italy it ranks eighth in the grade of the main risk factors for the health of the population and is responsible for tens of thousands of premature deaths and a significant increase in morbidity for many chronic diseases (www.VIIAS.it; EEA report 2018, https://www.eea.europa.eu/highlights/air-pollution-still-too-high). Reducing exposure to air pollution is therefore essential to achieve the target of reducing 
premature CVD mortality by $25 \%$ by 2025 as proposed by the World Heart Federation [3].

The cardiovascular risk attributable to pollution can be quantified and can be modified by population-based risk removal interventions, but individual interventions are also important [4]. The National Health Service (NHS) in general, and health personnel in particular, have an important role in reducing the global CVD burden attributable to air pollution. The NHS has first and foremost an important advocacy role, i.e. the responsibility to bring other sectors (transport, industry, agriculture, urban planning) to consider health, and the possible direct and indirect health consequences of air pollution. The "health in all" WHO policy is a strong incentive for economic and development choices to consider the costs associated with pollution and the need for environmental promotion. Doctors and health personnel, because of the role they play in society, have the responsibility to ask in all possible instances for the reduction of emission sources. However, as with other traditional risk factors for CVD (e.g., cholesterol or blood pressure levels), physicians can identify patients at high risk of exposure to air pollution and provide recommendations and interventions to reduce the individual risk of CVD.

Unfortunately, there is no established approach on this issue on how to frame air pollution and CVD risk at individual level, and most physicians do not have the necessary tools and collaboration network to assess the risk of exposure in their patient population and to provide intervention recommendations to high-risk patients. This contribution is intended to provide stimuli and guidance, also based on indications from a specific publication in the United States [5].

\section{3. - Air pollutants, sources and emission}

Air pollution is a complex mixture of air pollutants, the main ones being air particulate matter (PM) and gaseous pollutants such as ozone, nitrogen dioxide $\left(\mathrm{NO}_{2}\right)$, volatile organic compounds, carbon monoxide $(\mathrm{CO})$ and sulphur dioxide $\left(\mathrm{SO}_{2}\right)$. Atmospheric particulate matter varies in composition and size and it is a mixture of solid particles containing carbonaceous material, combustion residue, other organic substances (such as polycyclic aromatic hydrocarbons), inorganic metals and ions and gaseous substances trapped in particles such as $\mathrm{NO}_{2}, \mathrm{SO}_{2}$ and $\mathrm{CO}[6]$.

$\mathrm{PM}$ is generally divided into three size classes corresponding to its ability to penetrate the respiratory tract, on which the intensity and severity of the harmful effects depend.

- PM10 - particulate matter consisting of particles with a diameter $<10 \mu \mathrm{m}$, an inhalable dust, i.e. capable of penetrating the upper respiratory tract (nose, pharynx and larynx).

- PM2.5 - fine particulate matter with a diameter $<2.5 \mu \mathrm{m}$, capable of penetrating the tracheobronchial tract (trachea, bronchioles).

- UFP, ultrafine particulates: diameter $<0.1 \mu \mathrm{m}$, they are able to penetrate deeply into the lungs up to the alveoli. 
The chemical components of PM2.5 vary according to the emission source and include elemental carbon, transition metals, complex organic molecules, sulphate, nitrate, soil and dust [7].

In our country, the main source of air pollution, especially in urban areas, is still represented by the exhausts of vehicular traffic, in particular diesel engines; however, it has also been recognized in recent years the important role of biomass combustion (such as wood and pellets used for heating), which are highly polluting and responsible for an increase in the concentration of PM especially in northern and rural areas. In addition to these polluting sources, there are other important ones. Agriculture and livestock farming contribute considerably due to ammonia emissions, which are transformed into secondary particulate matter by chemical transformation in the atmosphere. Finally, there are industrial emissions. The epidemiological study Sentieri [8] has considered all the large industrial areas with a strong environmental pressure in the country, demonstrating that, even adjusting for the socioeconomic level of the inhabitants, the health status of the population in these areas is compromised. Moreover, the Italian cases due to the industrialization of the $60 \mathrm{~s}$ and $70 \mathrm{~s}$ are on the media. Just to name a few, starting from the south, the industrial complexes of Gela and Augusta in Sicily, Taranto and Brindisi in Puglia, Civitavecchia in Lazio, and Acna di Cengio in Liguria.

The European Union issues directives for the control of environmental pollution with the limit values of the concentration of pollutants and Italy adopts the European legislation. However, many European countries, including Italy, do not actually comply with the regulations. In urban areas of our country, the limits indicated are exceeded. Nitrogen dioxide, a gas with toxic action, is above the annual limit allowed by European directives in many urban areas. Large areas, such as the Po Valley, are above the limits for PM10 and PM2.5. For this reason, Italy is subject to infringement procedures by the European Community. But the problem is not only the regulation, but a fundamental contradiction of the system. The WHO recommends in fact much lower concentration values of pollutants than those prescribed by European legislation (the WHO Air Quality Guidelines for the protection of human health). There is a major discrepancy between what is prescribed by law at European level and what is recommended by the WHO as guide values for air quality that is not harmful to health. For example, the limit value of the annual average PM2.5 is $25 \mu \mathrm{g} / \mathrm{m}^{3}$ for European legislation (and therefore also for Italian legislation) while the WHO guidelines are much stricter and recommend a value of $10 \mu \mathrm{g} / \mathrm{m}^{3}$ to protect the health of the population, a significant difference.

\section{4. - How to measure or estimate air pollution}

4*1. Qualitative evaluation. - The simplest way to get an idea of the possible individual exposure to pollutants is through a simple medical history. Few questions can easily be added to the list of questions that doctors and health professionals already normally ask the patient, such as diet, exercise, smoking, alcohol and other cardiac risk factors. Examples of these questions can be: 
1) Do you live or work near a busy road?

2) Do you live or work near an industrial centre?

3) Are you aware of other sources of pollution near your home?

4) Do you spend a lot of time driving or travelling in traffic?

5) Do you exercise outdoors on busy roads?

The proximity to a few hundred metres of multi-lane or high-speed roads is a good proxy for exposure to air pollution from road traffic. Other factors that can increase exposure to road traffic pollution include commuting during rush hour, driving in traffic with car windows open or using air conditioning with outdoor circulation, and physical exertion outdoors. The risk of cardiovascular events is higher for patients exercising in polluted environments, particularly on hot days or during peak hours, when pollution levels may be high.

Living close to a major industrial centre can pose a health risk. These areas generally have multiple sources of PM2.5 emissions, such as factories, refineries, power plants and road traffic. For patients living in rural or less developed areas, it is important to ask about the proximity to small industries, seasonal agricultural fires, occasional burning of waste and the use of solid fuels for domestic heating.

4.2. Quantitative assessment. - Measuring air quality through the system of fixed monitors organized by the Regional Environmental Protection Agencies (ARPA) aims to improve the scientific understanding of air pollution and to assess its impact on health. The measures are vital to determine when legally binding limits set by the European Union and national legislation are exceeded. By analysing the data, it is possible to know the daily air pollution levels, to identify areas of the city that are better or worse than others, and to understand whether pollutant concentrations are increasing or decreasing. It is possible to study how pollutants interact with each other and how they are related to traffic intensity. When studying the relationship between climate conditions and air quality, it is also possible to predict which weather conditions will give rise to intense pollution episodes. Measurement of air pollution allows experts to predict future scenarios using advanced modelling techniques. This information is used by administrators to make informed decisions to control vehicle emissions and to reduce the number of vehicles allowed to circulate. Environmental policy is therefore constantly updated in the light of the results of scientific research. The air quality monitoring system in Italy is very advanced and each region provides the public with information on air quality through its channels and via the internet. This information is also accompanied by air quality forecasts in the following days (usually up to 72 hours). In this way it is possible to know in detail the environmental conditions and to know the critical situations.

A theoretically more accurate way to quantify an individual's exposure is to use personal monitoring devices. Most of these devices are expensive, bulky, noisy and difficult to wear for long periods of measurement. However, recent developments in low-cost, 
lightweight, wearable devices may soon facilitate personal monitoring of PM2.5, with possible integration into mobile phones, wristwatches or other personal electronic devices. Furthermore, pollutant dispersion modelling is becoming established as a complementary tool in assessing the exposure of the resident population to air pollution. Statistical models can generate estimates of pollutant concentrations at the individual's home or work address.

In Italy, several regions have developed sophisticated models to estimate the average levels of pollutants in every point of the territory, not only where fixed control units exist. These models consider that the mechanisms that intervene in the dispersion of air pollutants are linked to meteorology, the orography of the territory and the chemicalphysical transformations that pollutants undergo in the atmosphere. The dispersion models take these aspects into account and provide concentration maps that represent the ground footprint of the emission source. These maps can therefore be used to assign an exposure level to a residential address in each area. More recently, these models have been supplemented by satellite observations (Aerosol Optical Depth - AOD) from NASA (National Aeronautics and Space Administration) satellite instruments. In particular, the sensor detects the amount of radiant light that is absorbed or refracted by the particles in suspension and, based on this information, produces an estimate of the level of aerosol present inside the air column. The AOD parameter is detected by the MODIS (Moderate Resolution Imaging Spectroradiometer) sensor, a spectroradiometer on board the NASA Earth (Eos AM) and Aqua (eos PM) satellites.

\section{5. - Epidemiological studies and mechanism of action of air pollutants}

Both the American Heart Association and the European Society of Cardiology recognise PM2.5 as a cardiovascular risk factor. Results of toxicological and experimental studies indicate that particles, once inhaled, travel to the alveoli of the lung where they trigger a cascade of pathophysiological events, primarily an inflammatory process with secretion of systemic inflammation mediators. A small fraction of the ultrafine particles (and of metals and organic compounds) passes the alveolar-capillary barrier and enters the systemic circulation. These processes together cause oxidative stress and systemic inflammation, resulting in increased vasoconstriction, increased blood pressure, increased heart rate, insulin resistance, endothelial dysfunction, platelet aggregation, increased thrombogenicity and instability of arteriosclerotic plaque. Acute exposures to PM2.5 through these mechanisms may cause an increase in the frequency of ischemic heart attacks, stroke, heart failure, venous thromboembolism, arrhythmias and increased hospital admissions and mortality due to cardiovascular causes. Similarly, prolonged exposures to PM2.5 also increase the risk of developing hypertension, diabetes mellitus, high-density lipoprotein dysfunction, atherosclerotic disease, metabolic syndrome and cardiovascular mortality $[4,6,9]$.

Air pollution can exert its effects on health for both acute, short-term exposures and chronic, long-term exposures. Numerous studies have been conducted, also in Italy, and they have confirmed that air pollutants, in particular PM10, PM2.5, and nitrogen 
dioxide $\left(\mathrm{NO}_{2}\right)$, increase the risk of cardiovascular mortality and non-fatal cardiovascular events $[4,9,10]$. Of particular interest for Italy are the studies on short-term effects that have been carried out in many cities in the framework of the EPIAIR (decade 2000-2010) and MEDPARTICLES projects. Short-term exposures were associated with the onset of acute diseases such as myocardial infarction or stroke after a few days, or even death in the case of susceptible individuals [11-16]. As far as long-term effects are concerned, the longitudinal study of the population of Rome enrolled in the 2001 census [17] and the European multicentre study ESCAPE (European Study of Cohorts for Air Pollution Effects - www.escapeproject.eu), in which the cities of Rome, Turin and Varese took part, are worth mentioning. The ESCAPE project studied the chronic effects of air pollution in adult cohorts. The results of ESCAPE show an association between chronic exposure to air pollutants and natural mortality and cardiovascular events [17-20] and lung, brain, breast and digestive tract cancer [20-24].

The recent joint statement of the European Respiratory Society and the American Respiratory Society clarifies the broad spectrum of adverse effects of pollution, including on "new" diseases such as neurological and metabolic diseases not previously studied [25].

\section{6. - Physicians and their patients}

Effective measures to reduce pollution include enforcement of air quality standards, reduction of industrial emissions, transition to clean fuels and renewable energy sources, reduction of traffic in urban areas, enforcement of energy efficiency standards, reduction of emissions from cars and improved access to public transport and sustainable mobility. Advocacy efforts can benefit from reference to global targets, such as the WHO recommendation to keep PM2.5 exposure below an annual average of $10 \mu \mathrm{g} / \mathrm{m}^{3}$ and below $25 \mu \mathrm{g} / \mathrm{m}^{3}$ over 24 hours [14].

Air pollution reduction interventions are typically outside the scope of clinical practice. However, the role of physicians is crucial in identifying those subjects highly susceptible to cardiovascular and respiratory effects attributable to high levels of air pollution. Physician has a central role in the clinical management of air pollution exposure, namely deciding which individuals should receive advice and guidance. The first question a doctor asks himself is who are the patients most susceptible to air pollution? Who are those who are most at risk of developing a cardiovascular or respiratory disease at the same level of exposure to air pollution. Advanced age, low socioeconomic status, obesity and traditional cardiac risk factors (e.g., hypertension, diabetes mellitus, dyslipidemia, metabolic syndrome) characterize the population of those susceptible to the effects of air pollution $[4,6]$. And of course, vulnerable people are those residentially exposed to higher levels of air pollution. In the EPIAIR study conducted in several Italian cities it was found that older people, especially during the summer period, who had previous hospitalizations for chronic cardio-respiratory diseases (in particular arrhythmia, cardiac conduction disorders and heart failure) and with diabetes had an increased risk of death associated with acute exposure to PM [16]. 
Observational studies conducted on adult populations in both the United States and Europe show that reduced exposure to air pollution rapidly reduces the immediate risk of acute coronary syndromes, heart failure, stroke and arrhythmia. Therefore, physicians can inform their patients about the risks associated with exposure to air pollution by encouraging them to behave in a way that reduces exposure. Patients can be advised to avoid the main roads during rush hour, keep car windows closed, keep air filtration systems in the car and keep the air circulating inside. Increased awareness of air quality indexes, together with advice from health care professionals, can significantly change individual behaviour [26]. Similarly, mobile phone applications, websites and informal communication through social media can help individuals to plan their activities to minimise exposure to pollution. On heavily polluted days, for example, the susceptible population could keep their windows closed at home and limit prolonged or heavy outdoor efforts $[4,6]$. Intensive activities and exercise can be planned when particle levels are lower, conducted indoors or in parks and gardens rather than near major roads. The short-term beneficial effects of physical activity could be reduced (although not completely eliminated) by air pollution. At the same level of exposure, patients with pre-existing conditions benefit less from physical activity than healthy ones $[3,5]$. However, people should not be discouraged from walking or cycling because the cardiovascular benefit of these activities outweighs the risk associated with inhalation of particulate matter [27]. On the other hand, poor air quality may inhibit the physical activity of the resident population.

Public health bodies such as the WHO, the American Heart Association and the European Society of Cardiology do not currently have recommendations on the use of portable air pollution masks or purifiers. In clinical settings, medical staff and patients wear disposable masks to reduce the likelihood of contracting or transmitting infections, but there is still limited evidence of the effectiveness of the use of masks against particulate matter in different situations [28]. In a recent comment, Huang and Morawska warned about the false sense of security that the use of a mask can feed. Many factors need to be taken into account, including the type of mask, the shape of the face, the size and sources of particulate matter, and especially the behaviour of the wearer. Masks are uncomfortable to wear for a long time, on hot days they can make it difficult to breathe, carbon dioxide can accumulate causing drowsiness, the filter can get wet, altering its performance, people can use the same mask for a long time to save money and risk breathing through a clogged filter [29].

Evidence of dietary supplements, antioxidant vitamins, and omega-3 polyunsaturated fatty acids to prevent the effects of air pollution is also inconclusive [30].

\section{7. - Conclusions}

Outdoor air pollution is a well-established risk factor for cardiovascular and respiratory disease, responsible for a global burden of ischemic diseases and strokes that is even greater than the individual different traditional cardiac risk factors. Reducing the risk attributable to pollution requires multi-sectoral policies and programmes to reduce air 
pollution emissions and exposures at local, regional and international level. The greatest benefits can only be achieved through a strong synergy between the environmental and health care sectors with interventions ranging from emission regulation, implementation of air quality standards, sharing of exposure data, and planning of tailor-made interventions for the patient to reduce individual exposure. Scientists, doctors and health professionals, however, can do much to inform patients and prevent adverse effects in people at high risk.

\section{REFERENCES}

[1] World Urbanization Prospects, The 2014 Revision Highlights (United Nations) 2014.

[2] GBD 2016 Risk Factors Collaborators, "Global, regional, and national comparative risk assessment of 84 behavioural, environmental and occupational, and metabolicrisks or clusters of risks, 1990-2016: a systematic analysis for the Global Burden of Disease Study 2016", Lancet, 390 (2017) 1345.

[3] Sacco R. L., Roth G. A., Reddy K. S., Arnett D. K., Bonita R., Gaziano T. A., Heidenreich P. A., Huffman M. D., Mayosi B. M., Mendis S., Murray C. J., Perel P., Piñeiro D. J., Smith S. C. jr., Taubert K. A., Wood D. A., Zhao D. and Zoghis W. A., "The heart of 25 by 25 : achieving the goal of reducing global and regional premature deaths from cardiovascular diseases and stroke: a modeling study from the American Heart Association and World Heart Federation", Circulation, 133 (2016) e674.

[4] Brook R. D., Rajagopalan S., Pope C. A. 3rd, Brook J. R., Bhatnagar A., Diez-Roux A. V., Holguin F., Hong Y., Luepker R. V., Mittleman M. A., Peters A., Siscovick D., Smith S. C. jr., Whitsel L., Kaufman J. D., American Heart Association Council on Epidemiology and Prevention, Council on the Kidney in Cardiovascular Disease, Council on Nutrition, Physical Activity And Metabolism, "Particulate matter air pollution and cardiovascular disease: an update to the scientific statement from the American Heart Association", Circulation, 121 (2010) 2331.

[5] Hadley B. M. and Vedanthan R., "Developing a Clinical Approach to Air Pollution and Cardiovascular Health", Circulation, 137 (2018) 725.

[6] Newby D. E., Mannucci P. M., Tell G. S., Baccarelli A. A., Brook R. D., Donaldson K., Forastiere F., Franchini M., Franco O. H., Graham I., Hoek G., Hoffmann B., Hoylaerts M. F., Künzli N., Mills N., Pekkanen J., Peters A., Piepoli M. F., Rajagopalan S., Storey R. F., ESC Working Group on Thrombosis, European Association for Cardiovascular Prevention and Rehabilitation, ESC Heart Failure Association, "Expert position paper on air pollution and cardiovascular disease", Eur. Heart J., 36 (2015) 83.

[7] Secrest M. H., Schauer J. J., Carter E. M. and Baumgartner J., "Particulate matter chemical component concentrations and sources in settings of household solid fuel use", Indoor Air, 27 (2017) 1052.

[8] Pirastu R., Pasetto R., Zona A., Ancona C., Iavarone I., Martuzzi M. and Comba P., "The health profile of populations living in contaminated sites: SENTIERI approach", J. Environ. Public Health, 2013 (2013) 939267.

[9] Rückerl R., Schneider A., Breitner S., Cyrys J. and Peters A., "Health effects of particulate air pollution: a review of epidemiological evidence", Inhal. Toxicol., 23 (2011) 555 . 
[10] Münzel T., Sørensen M., Gori T., Schmidt F. P., Rao X., Brook F. R., Chen L. C., Brook R. D. and Rajagopalan S., "Environmental stressors and cardio-metabolic disease: part II-mechanisticinsights", Eur. Heart J., 38 (2017) 557.

[11] Belleudi V., Faustini A., Stafoggia M., Cattani G., Marconi A., Perucci C. A. et al., "Impact of fine and ultrafine particles on emergency hospital admissions for cardiac and respiratory diseases", Epidemiology, 21 (2010) 414.

[12] Alessandrini E. R., Stafoggia M., Faustini A., Berti G., Canova C., De Togni A., Di Biagio K., Gherardi B., Giannini S., Lauriola P., Pandolfi P., Randi G., Ranzi A., Simonato L., Zauli Sajani S., Cadum E. and Forastiere F., on behalf of the EpiAir2 Study Group, "Association Between Short-Term Exposure to PM2.5 and PM10 and Mortality in Susceptible Subgroups: A Multisite Case-Crossover Analysis of Individual Effect Modifiers", Am. J. Epidemiol., 184 (2016) 744.

[13] Renzi M., Stafoggia M., Faustini A., Cesaroni G., Cattani G., and Forastiere F., "Analysis of Temporal Variability in the Short-term Effects of Ambient Air Pollutants on Nonaccidental Mortality in Rome, Italy (1998-2014)", Environ. Health Perspect., 125 (2017) Issue No. 6.

[14] Stafoggia M., Schneider A., Cyrys J., Samoli E., Andersen Z. J., Bedada G. B., Bellander T., Cattani G., Eleftheriadis K., Faustini A., Hoffmann B., Jacquemin B., Katsouyanni K., Massling A., Peknanen J., Perez N., Peters A., Quass U., Yli-Tuomi T., Forastiere F., UF\&HEAlth Study Group, "Association Between Short-term Exposure to Ultrafine Particles and Mortality in Eight European Urban Areas", Epidemiology, 28 (2017) 172.

[15] Basagaña X., Jacquemin B., Karanasiou A., Ostro B., Querol X., Agis D., Alessandrini E., Alguacil J., Artiñano B., Catrambone M., de la Rosa J. D., Díaz J., Faustini A., Ferrari S., Forastiere F., Katsouyanni K., Linares C., Perrino C., Ranzi A., Ricciardelli I., Samoli E., Zauli-Sajani S., Sunyer J. and StAFoggia M., on behalf of the MED-PARTICLES STUdy GRoup, "Short-term effects of particulate matter constituents on daily hospitalizations and mortality in five SouthEuropean cities: results from the MED-PARTICLES project", Environ. Int., 75 (2015) 151.

[16] Alessandrini E. R., Faustini A., Chiusolo M., Stafoggia M., Gandini M., Demaria M., Antonelli A., Arena P., Biggeri A., Canova C., Casale G., Cernigliaro A., Garrone E., Gherardi B., Gianicolo E. A., Giannini S., Iuzzolino C., Lauriola P., Mariottini M., Pasetto P., Randi G., Ranzi A., Santoro M., Selle V., Serinelli M., Stivanello E., Tominz R., Vigotti M. A., Zauli-Sajani S., Forastiere F., Cadum E., Gruppo collaborativo EpiAir2, "Air pollution and mortality in twenty-five Italian cities: results of the EpiAir2 Project", Epidemiol. Prev., 37 (2013) 220.

[17] Cesaroni G., Forastiere F., Stafoggia M., Andersen Z. J., Badaloni C., Beelen R., Caracciolo B., de Faire U., Erbel R., Eriksen K. T., Fratiglioni L., Galassi C., Hampel R., Heier M., Hennig F., Hilding A., Hoffmann B., Houthuijs D., Jöckel K. H., Korek M., Lanki T., Leander K., Magnusson P. K., Migliore E., Ostenson C. G., Overvad K., Pedersen N. L., Juha Pekkanen J., Penell J., Pershagen G., Pyko A., Raaschou-Nielsen O., Ranzi A., Ricceri F., Sacerdote C., Salomaa V., Swart W., Turunen A. W., Vineis P., Weinmayr G., Wolf K., de Hoogh K., Hoek G., Brunekreef B. and Peters A., "Long term exposure to ambient air pollution and incidence of acute coronary events: prospective cohort study and meta-analysis in 11 European cohorts from the ESCAPE Project", BMJ, 21 (2014) 348 . 
[18] Beelen R., Stafoggia M., Raaschou-Nielsen O., Andersen Z. J., Xun W. W., Katsouyanni K., Dimakopoulou K., Brunekreef B., Weinmayr G., Hoffmann B., Wolf K., Samoli E., Houthuijs D., Nieuwenhuijsen M., Oudin A., Forsberg B., Olsson D., Salomaa V., Lanki T., Yli-Tuomi T., Oftedal B., Aamodt G., Nafstad P., De Faire U., Pedersen N. L., Östenson C. G., Fratiglioni L., Penell J., Korek M., Pyko A., Eriksen K. T., Tuønneland A., Becker T., Eeftens M., Bots M., Meliefste K., Wang M., Bueno-de-Mesquita B., Sugiri D., Krämer U., Heinrich J., De Hoogh K., Key T., Peters A., Cyrys J., Concin H., Nagel G., Ineichen A., Schaffner E., Probst-Hensch N., Dratva J., Ducret-Stich R., Vilier A., Clavel-Chapelon F., Stempfelet M., Grioni S., Krogh V., Tsai M. Y., Marcon A., Ricceri F., Sacerdote C., Galassi C., Migliore E., Ranzi A., Cesaroni G., Badaloni C., Forastiere F., Tamayo I., Amiano P., Dorronsoro M., Katsoulis M., Trichopoulou A., Vineis P. and Hoek G., "Long-term exposure to air pollution and cardiovascular mortality: an analysis of 22 European cohorts", Epidemiology, 25 (2014) 368.

[19] Stafoggia M., Cesaroni G., Peters A., Andersen Z. J., Badaloni C., Beelen R., Caracciolo B., Cyrys J., de Faire U., de Hoogh K., Eriksen K. T., Fratiglioni L., Galassi C., Gigante B., Havulinna A. S., Hennig F., Hilding A., Hoek G., Hoffmann B., Houthuijs D., Korek M., Lanki T., Leander K., Magnusson P. K., Meisinger C., Migliore E., Overvad K., Ostenson C. G., Pedersen N. L., Pekkanen J., Penell J., Pershagen G., Pundt N., Pyko A., Rahaschou-Nielsen O., Ranzi A., Ricceri F., Sacerdote C., Swart W. J., Turunen A. W., Vineis P., Weimar C., Weinmayr G., Wolf K., Brunekreef B. and Forastiere F., "Long-term exposure to ambient air pollution and incidence of cerebrovascular events: results from 11 European cohorts within the ESCAPE project", Environ. Health Perspect., 122 (2014) 919.

[20] Fuks K. B., Weinmayr G., Basagaña X., Gruzieva O., Hampel R., Oftedal B., Sørensen M., Wolf K., Aamodt G., Aasvang G. M., Aguilera I., Becker T., Beelen R., Brunekreef B., Caracciolo B., Cyrys J., Elosua R., Eriksen K. T., Foraster M., Fratiglioni L., Hilding A., Houthuijs D., Korek M., Künzli N., Marrugat J., Nieuwenhuijsen M., Östenson C. G., Penell J., Pershagen G., Raaschou-Nielsen O., Swart W. J. R., Peters A. and Hoffmann B., "Long-term exposure to ambient air pollution and traffic noise and incident hypertension in seven cohorts of the European study of cohorts for air pollution effects (ESCAPE)", Eur. Heart J., 38 (2017) 983.

[21] RaAschou-Nielsen O., Andersen Z. J., Beelen R., Samoli E., Stafoggia M., Weinmayr G., Hoffmann B., Fischer P., Nieuwenhuijsen M. J., Brunekreef B., Xun W. W., Katsouyanni K., Dimakopoulou K., Sommar J., Forsberg B., Modig L., Oudin A., Oftedal B., Schwarze P. E., Nafstad P., De Faire U., Pedersen N. L., Ostenson C. G., Fratiglioni L., Penell J., Korek M., Pershagen G., Eriksen K. T., Sørensen M., Tuønneland A., Ellermann T., Eeftens M., Peeters P. H., Meliefste K., Wang M., Bueno-de-Mesquita B., Key T. J., De Hoogh K., Concin H., Nagel G., Vilier A., Grioni S., Krogh V., Tsai M. Y., Ricceri F., Sacerdote C., Galassi C., Migliore E., Ranzi A., Cesaroni G., Badaloni C., Forastiere F., Tamayo I., Amiano P., Dorronsoro M., Trichopoulou A., Bamia C., Vineis P. and Hoek G., "Air pollution and lung cancer incidence in 17 European cohorts: prospective analyses from the European Study of Cohorts for Air Pollution Effects (ESCAPE)", Lancet Oncol., 14 (2013) 813.

[22] Nagel G., Stafoggia M., Pedersen M., Andersen Z. J., Galassi C., Munkenast J., Jaensch A., Sommar J., Forsberg B., Olsson D., Oftedal B., Krog N. H., 
Aamodt G., Pyko A., Perhhagen G., Korek M., De Faire U., Pedersen N. L., Östenson C. G., Fratiglioni L., Sørensen M., Tuønneland A., Peeters P. H., Bueno-de-Mesquita B., Vermeulen R., Eeftens M., Plusquin M., Key T. J., Concin H., Lang A., Wang M., Tsai M. Y., Grioni S., Marcon A., Krogh V., Ricceri F., Sacerdote C., Ranzi A., Cesaroni G., Forastiere F., Tamayo-Uria I., Amiano P., Dorronsoro M., De Hoogh K., Beelen R., Vineis P., Brunekreef B., Hoek G., RaAschou-Nielsen O. and Weinmayr G., "Air pollution and incidence of cancers of the stomach and the upper aerodigestive tract in the European Study of Cohorts for Air Pollution Effects (ESCAPE)", Int. J. Cancer, 143 (2018) 1632.

[23] Andersen Z. J., Stafoggia M., Weinmayr G., Pedersen M., Galassi C., Jørgensen J. T., Oudin A., Forsberg B., Olsson D., Oftedal B., Aasvang G. M., Aamodt G., Pyko A., Pershagen G., Korek M., De Faire U., Pedersen N. L., Östenson C. G., Fratiglioni L., Eriksen K. T., Tuønneland A., Peeters P. H., Bueno-de-Mesquita B., Plusquin M., Key T. J., Jaensch A., Nagel G., Lang A., Wang M., Tsai M. Y., Fournier A., Boutron-Ruault M. C., Baglietto L., Grioni S., Marcon A., Krogh V., Ricceri F., Sacerdote C., Migliore E., Tamayo-Uria i., Amiano P., Dorronsoro M., Vermeulen R., Sokhi R., Keuken M., de Hoogh K., Beelen R., Vineis P., Cesaroni G., Brunekreef B., Hoek G. and RaAschou-Nielsen O., "Long-Term Exposure to Ambient Air Pollution and Incidence of Postmenopausal Breast Cancer in 15 European Cohorts within the ESCAPE Project", Environ. Health Perspect., 125 (2017) 107005.

[24] Andersen Z. J., Pedersen M., Weinmayr G., Stafoggia M., Galassi C., Jørgensen J. T., Sommar J. N., Forsberg B., Olsson D., Oftedal B., Aasvang G. M., Schwarze P., Pyko A., Pershagen G., Korek M., Faire U., Östenson C. G., Fratiglioni L., Eriksen K. T., Poulsen A. H., Tuønneland A., Bräuner E. V., Peeters P. H., Bueno-de-Mesquita B., Jaensch A., Nagel G., Lang A., Wang M., Tsai M. Y., Grioni S., Marcon A., Krogh V., Ricceri F., Sacerdote C., Migliore E., Vermeulen R., Sokhi R., Keuken M., de Hoogh K., Beelen R., Vineis P., Cesaroni G., Brunekreef B., Hoek G. and Raaschou-Nielsen O., "Long-term exposure to ambient air pollution and incidence of brain tumor: the European Study of Cohorts for Air Pollution Effects (ESCAPE)", Neuro Oncol., 19 (2018) 420.

[25] Thurston G. D., Kipen H., Annesi-Maesano I., Balmes J., Brook R. D., Cromar K., De Matteis S., Forastiere F., Forsberg B., Frampton M. W., Grigg J., Heederik D., Kelly F. J., Kuenzli N., Laumbach R., Peters A., Rajagopalan S. T., Rich D., Ritz B., Samet J. M., Sandstrom T., Sigsgandd T., Sunyer J. and BRUNEKREEF B., "A joint ERS/ATS policy statement: what constitutes an adverse health effect of air pollution? An analytical framework", Eur. Respir. J., 49 (2017) 1600419.

[26] Wen X. J., Balluz L. and Mokdad A., "Association between media alerts of air quality index and change of outdoor activity among adult asthma in six states, BRFSS, 2005", J. Community Health, 34 (2009) 40.

[27] Cepeda M., Schoufour J., Freak-Poli R., Koolhaas C. M., Dhana K., Bramer W. M. and Franco O. H., "Levels of ambient air pollution according to mode of transport: a systematic review", Lancet Public Health, 2 (2017) e23.

[28] Bin-Reza F., Lopez Chavarrias V., Nicoll A. and Chamberland M. E., "The use of masks and respirators to prevent transmission of influenza: a systematic review of the scientific evidence", Influenza Other Respir. Viruses, 6 (2012) 257.

[29] Huang Wei and MoraWska Lidia, "Face masks could raise pollution risks", Nature, $\mathbf{5 7 4}$ (2019) 29.

[30] Romieu I., Castro-Giner F., Kunzli N. and Sunyer J., "Air pollution, oxidative stress and dietary supplementation: a review", Eur. Respir. J., 31 (2008) 179. 